\title{
Review: donepezil improves clinical state in mild or moderate Alzheimer's disease
}

\author{
Birks JS, Melzer D. The efficacy of donepezil for mild and moderate Alzheimer's disease. (Cochrane Review, latest version 21 Aug, \\ 1998). In: Cochrane Library. Oxford: Update Software.
}

\section{Question}

In patients with mild or moderate Alzheimer's disease, does donepezil improve wellbeing?

\section{Data sources}

Studies were identified by searching Medline, PsycLIT, EMBASE/Excerpta Medica, and the Cochrane Controlled Trials Register; reviewing conference papers and bibliographies of relevant articles; and contacting experts.

\section{Study selection}

Studies were selected if they were double blind, randomised trials of donepezil (used for $\geqslant 1$ day) in patients with probable Alzheimer's disease diagnosed by an acceptable criterion.

\section{Data extraction}

Data were extracted on patient characteristics, interventions used, study quality, cognitive functioning, global clinical impression, quality of life, dependency, functional performance, behavioural disturbance, effect on caregiver, death, treatment acceptability, and adverse effects.

\section{Main results}

4 studies (1920 patients) that compared donepezil with placebo (treatment durations from 12-24 weeks) met the inclusion criteria. 1 study (818 patients), was excluded because it did not have sufficient data; therefore, 3 studies (1102 patients, mean age 73 y) were included in the analysis. Cognitive function was improved by donepezil compared with placebo, shown by improved scores on the cognitive subscale of the Alzheimer's Disease Assessment Scale (ADAS-Cog) (weighted mean difference [WMD] -3.0, 95\% CI -3.9 to -2.1 for $10 \mathrm{mg} / \mathrm{d}$ of donepezil $v$ placebo, and WMD $-2.6,-3.5$ to -1.8 for $5 \mathrm{mg} / \mathrm{d}$ of donepezil $v$ placebo) and the
Mini Mental State Examination (WMD 1.3, CI 0.8 to 1.8 for 10 $\mathrm{mg} / \mathrm{d}$ of donepezil $v$ placebo, and WMD 1.1, CI 0.5 to 1.6 for 5 $\mathrm{mg} / \mathrm{d}$ of donepezil $v$ placebo). Fewer patients in the donepezil groups than those in the placebo group had unchanged or worsened global clinical states (table). Compared with placebo, more patients withdrew from donepezil treatment before study completion in the $10 \mathrm{mg}$ group (table) but not the $5 \mathrm{mg}$ group $\{13 \%$ v $15 \%, \mathrm{p}=0.39\} *$. No difference existed between groups for quality of life.

\section{Conclusion}

Donepezil improves cognitive function and global clinical states but not quality of life in patients with mild or moderate Alzheimer's disease.

*p value calculated from data in article.

Donepezil v placebo in mild or moderate Alzheimer's disease $\dagger$

\begin{tabular}{lllll}
\hline $\begin{array}{l}\text { Outcomes at } 12 \text { to } \\
\text { 24 weeks }\end{array}$ & $\begin{array}{l}\text { Domepezil } \\
\text { dose }\end{array}$ & $\begin{array}{l}\text { Weighted } \\
\text { comparison }\end{array}$ & RRR (95\% CI) & NNT (CI) \\
\hline $\begin{array}{l}\text { Unchanged or } \\
\text { worsened global } \\
\text { clinical states }\end{array}$ & $\begin{array}{l}10 \mathrm{mg} / \text { day } \\
5 \mathrm{mg}\end{array}$ & $70 \% v 86 \%$ & $19 \%(10$ to 27$)$ & $7(5$ to 10$)$ \\
& & & $\begin{array}{l}\text { RRI (CI) } \\
7(5 \text { to } 13)\end{array}$ & NNH (CI) \\
Withdrawals & $10 \mathrm{mg} /$ day & $23 \% v 14 \%$ & $62 \%(15$ to 129$)$ & $12(7$ to 30$)$
\end{tabular}

†Abbreviations defined in glossary; RRR, RRI, NNT, NNH, and CI calculated from data in article.

Source of funding: UK Medical Research Council.

For correspondence: Mrs Jacqueline Birks, Medical Statistician, Department of Clinical Geratology, University of Oxford, Oxford OX2 6HE, UK. Fax +44 (0)1865 224108.

\section{Commentary}

If a patient of yours has a probable diagnosis of mild to moderate Alzheimer's disease, should you prescribe donepezil? This is the question Birks and Melzer are trying to answer in this meta-analysis. By pooling the data from 3 phase II/III studies they find there is a small, but statistically significant, beneficial effect over placebo, both for cognition measured by the ADAS-Cog and the Clinician's Interview-Based Impression of Change Scale (CIBIC). Although the evidence for subtle improvements in cognition with cholinesterase inhibitors is mounting, it remains just that-subtle.

There are various dangers in over interpreting data from phase II/III trials. As Birks and Melzer point out, the trial population is very healthy; most patients seen by clinicians in their day to day practice will be excluded from this type of study. Another problem is how far can we translate changes in outcome scores into meaningful everyday constructs?

The overall benefit in the 24 week trial $(\mathrm{NNT}=7$ for no deterioration in CIBIC) was better than the first 12 week trial $(\mathrm{NNT}=11)$. The real treatment effect therefore may be diluted by inclusion of the brief phase II trial. Furthermore, an open label study of the long term efficacy of donepezil showed benefits continued to accrue up to 98 weeks, ${ }^{1}$ with an estimated difference in ADAS-Cog scores of 11.6 each year for those on donepezil compared with no treatment. Although open label studies should be interpreted with more caution than randomised trials, these are encouraging data.

Cochrane reviews are regularly updated, and Birks and Melzer have only just begun. Other cholinesterase inhibitors have already been licensed (eg, rivastigmine) and more are on the way. Because these have the same mechanism of action, the trials evaluating their use should be considered in meta-analyses of this type. Independent large studies are now underway that will add to our knowledge of the utility of donepezil in everyday practice and improve the precision of the true effect size. Past experience suggests that as more studies are done, the effect lessens. Still, we will have to wait and see.

$$
\begin{array}{r}
\text { James P Warner, MB BS, MRCP(UK), } \\
\text { MRCPsych } \\
\text { Imperial College School of Medicine, } \\
\text { St Charles Hospital, } \\
\text { London, UK }
\end{array}
$$

1 Rogers SL, Friedhoff LT. Eur Neuropsychopharmacol 1998;8:67-75. 